
Journal

\title{
Distribution and contamination assessment of arsenic and mercury in surface sediments from the intertidal zone of Yantai Sishili Bay, China
}

\author{
Chen-Chen Wang, Da-Wei Pan, Hai-Tao Han \& Xue-Ping Hu
}

To cite this article: Chen-Chen Wang, Da-Wei Pan, Hai-Tao Han \& Xue-Ping Hu (2018) Distribution and contamination assessment of arsenic and mercury in surface sediments from the intertidal zone of Yantai Sishili Bay, China, Human and Ecological Risk Assessment: An International Journal, 24:8, 2024-2035, DOI: 10.1080/10807039.2018.1436435

To link to this article: https://doi.org/10.1080/10807039.2018.1436435

\section{Published online: 22 Feb 2018.}

Submit your article to this journal $\longleftarrow$

山 Article views: 56

View Crossmark data \lceil 


\title{
Distribution and contamination assessment of arsenic and mercury in surface sediments from the intertidal zone of Yantai Sishili Bay, China
}

\author{
Chen-Chen Wang ${ }^{\mathrm{a}}$, Da-Wei Pan ${ }^{\mathrm{a}, \mathrm{b}}$, Hai-Tao Han ${ }^{\mathrm{a}, \mathrm{b}}$, and Xue-Ping Hu $\mathrm{Hu}^{\mathrm{a}, \mathrm{b}}$ \\ ${ }^{a}$ Key Laboratory of Coastal Environmental Processes and Ecological Remediation, Yantai Institute of Coastal Zone \\ Research, Chinese Academy of Sciences, Yantai, P.R. China; 'University of Chinese Academy of Sciences, Beijing, \\ P.R. China
}

\begin{abstract}
Sixty surface sediment samples from the intertidal zone of Yantai Sishili Bay (YSB) have been analyzed for arsenic (As) and mercury ( $\mathrm{Hg}$ ) to evaluate their contamination levels and potential ecological risks. Concentrations of As and $\mathrm{Hg}$ ranged from 7.01-23.56 and 0.00-0.01 $\mu \mathrm{g}$ $\mathrm{g}^{-1}$ in the dry season; during the wet season, the corresponding data were 1.44-6.17 and $0.00-0.02 \mu \mathrm{g} \mathrm{g}^{-1}$. The geoaccumulation index $\left(I_{\text {geo }}\right)$ and potential ecological risk index $\left(E_{r}^{i}\right)$ were used to conduct a pollution assessment. The results demonstrated that the intertidal zone of YSB has good sediment quality and that $\mathrm{As}$ and $\mathrm{Hg}$ are not likely to cause negative environmental impacts in the region.
\end{abstract}

\section{ARTICLE HISTORY}

Received 28 November 2017

Revised manuscript

accepted 24 January 2018

\section{KEYWORDS}

mercury; arsenic; surface sediments; contamination assessment; Yantai Sishili Bay

\section{Introduction}

As the intersection of marine and terrestrial environments, the intertidal zone performs significant hydrological and ecological functions and is driven by both natural forces and human activities (Qian et al. 2016). Sediments accumulate at the junction of liquid and solid phases and are one of the major reservoirs of heavy metals from both natural and anthropogenic sources (Xu et al. 2016a; Zhang and Gao 2015). As environmental conditions change, sediments become a potential secondary source of heavy metals that could be released back into the water column (Pereira et al. 2015). For this reason, it is crucial to assess the levels of sediment contamination found in marine and other aquatic ecosystems (Xu et al. 2016b). Heavy metals in aquatic ecosystems have received extensive attention due to their toxicity, wide sources, nonbiodegradable properties, and accumulative behaviors (Zhuang and Gao 2014). When they enter intertidal zones, most heavy metals are deposited in sediments. As environmental conditions change, however, the heavy metals found in sediments can be released back into the water and pose a threat to the marine environment (Zhuang and Gao 2015a). Surveys of heavy metals found in intertidal sediments can therefore be used to assess the level of contamination in marine environments and provide basic information for evaluating environmental health risks.

CONTACT Da-Wei Pan dwpan@yic.ac.cn Eey Laboratory of Coastal Environmental Processes and Ecological Remediation, Yantai Institute of Coastal zone Research, Chinese Academy of Sciences, Chunhui Road 17, Yantai 264003, P.R. China.

Color versions of one or more of the figures in the article can be found online at www.tandfonline.com/bher. 
Arsenic (As) and mercury (Hg) are highly toxic heavy metals that accumulate primarily in sediments and are biomagnified through the food chain, resulting in remarkable ecological risks to benthic organisms, organisms that are dependent on sediments, and humans (Zhuang and Gao 2015a). As is a toxic metalloid ubiquitous in groundwater, soil, and sediments, and has acute, chronic toxic and carcinogenic effects on aquatic organisms as well as humans (Wang et al. 2016a). Hg and methylmercury (MeHg) are considered priority hazardous substances due to their adverse biological effects and environmental toxicity. High levels of $\mathrm{MeHg}$ can cause damage to the human brain and kidneys and also affect psychological plant activity like transpiration, mineral uptake, and photosynthesis (Haris et al. 2017). It is therefore important to monitor the concentrations of As and $\mathrm{Hg}$ to provide basic information for environmental risk assessments.

In recent years, there have been numerous studies on the sources, distribution, and contamination levels of heavy metals in sediments (Deng et al. 2013; Gati et al. 2016; Li et al. 2017; Zhao et al. 2016). Among them, some have focused on the study of heavy metals in the sediments of Shandong province ( $L i$ et al. 2016; Lin et al. 2016; Liu et al. 2014; Xu et al. 2013; Zhuang and Gao 2015a), which mainly concentrated on areas such as Jiaozhou Bay, Laizhou Bay, and the Yellow River Delta. Few studies have been carried out in Yantai Sishili Bay (YSB), which mainly focused on the nutrients, chlorophyll, hyperbenthos in the sediments, etc. (Hao et al. 2011; Li et al. 2013). As one of the most important areas of aquaculture in northern China and the primary region for aquaculture and tourism in Yantai, YSB has been influenced by anthropogenic activities, particularly industrial and domestic wastewater disposal. The intertidal zone of YSB is a typical sandy coast area in northern China under the influence of the rapid urbanization. Over the last two decades, the rapid development of the surrounding Yantai City had put a great stress on the marine ecosystem of YSB because of associated increases in population, aquaculture, wastewater discharge, and cargo throughput, which may lead to the input of heavy metals to YSB. For this reason, there is an increasing interest in studying the environmental quality of YSB, especially the concentrations of heavy metals.

Quantitative geochemical methods, including enrichment factor (EF), geoaccumulation index $\left(I_{\text {geo }}\right)$, and potential ecological risk factor $\left(\mathrm{E}_{\mathrm{r}}^{\mathrm{i}}\right)$, have been widely used to estimate the impacts that heavy metals have on sediment quality and the environment (Yi et al. 2016). $I_{\text {geo }}$ is particularly successful because it considers the effects of human activities; however, it ignores the differences in toxicity among individual metals. $\mathrm{E}_{\mathrm{r}}^{\mathrm{i}}$, on the other hand, comprehensively considers the differential effects of multiple contaminants and can make up for the deficiency of $I_{\text {geo }}$ (Liu et al. 2016). Hence, both $I_{\text {geo }}$ and $\mathrm{E}_{\mathrm{r}}{ }^{\mathrm{i}}$ are used to assess the contamination of heavy metals in this study. The main objectives of the study are (1) to estimate heavy metal concentrations and evaluate their contamination levels in intertidal sediments; (2) to evaluate the potential ecological risk of heavy metals; and (3) to analyze the distribution and possible sources of heavy metals in YSB in order to protect the environment of the bay and promote local economic development.

\section{Methods and materials}

\section{Study area}

YSB is an ear-shaped, semi-closed bay located in the Northern Yellow Sea, China, with a total surface area of about $130 \mathrm{~km}^{2}$, and with an average water depth of less than $15 \mathrm{~m}$ 
(Dong et al. 2012). The bay is an important harbor for Shandong province that supports marine aquaculture for the province's seafood market, and there are three important districts along the coast of Sishili Bay in Yantai: Zhifu, Laishan, and Muping. Also along the coastline is an estuary of the Guangdang River and an outlet of the Xin'anhe Sewage Plant, both of which may be potential and significant sources of heavy metal contamination in the bay due to rapid industrial and economic development in Yantai. Therefore, it is essential to assess the contamination of heavy metals in YSB to develop appropriate strategies and approaches for pollution control.

\section{Sediment sampling and pretreatment}

Two sampling expeditions were implemented in the intertidal zone of YSB in October 2014 and July 2015 (Figure 1). Sixty surface sediments $(0-5 \mathrm{~cm})$ were collected using grab samplers, including 15 surface sediments during the dry season (samples were taken in the supratidal, tidal, and infralittoral zones of each sampling section) and 45 surface sediments in the wet season (samples were taken in the supratidal, tidal, and infralittoral zones of each sampling section). After the samples were collected, surface sediments were stored in a plastic vessel and frozen at $-20^{\circ} \mathrm{C}$.

As and $\mathrm{Hg}$ were analyzed using Atomic Fluorescence Spectrometry (Beijing Ji Tian Instrument Co., AFS-930). First, the sediments were dried in a lyophilizer (Germany Christ), and then they were disaggregated and sieved through 160 mesh sieves. The sediments were then digested with an acid mixture $\left(\mathrm{HCl}: \mathrm{HNO}_{3}: \mathrm{H}_{2} \mathrm{O}=1: 3: 5\right)$ in a boiling water bath before final AFS analysis. Of the total number of samples, $20 \%(n=12)$ were selected for parallel sample detection, which found that the analysis was adequate. The quality assurance of the analytical procedures was validated using the Chinese national geostandard sample (GBW07333), and results were in accordance with the reference values. All the labwares (bottles, tubes, etc.) were pre-cleaned by soaking in $10 \% \mathrm{HNO}_{3}(\mathrm{w} / \mathrm{w})$ for at least $24 \mathrm{~h}$, followed by soaking and rinsing with deionized water. All reagents were guaranteed grade or higher level. Only ultrapure water was used for experimentation. All the analyses were done with analytical blanks to assure the proceedings reliability.

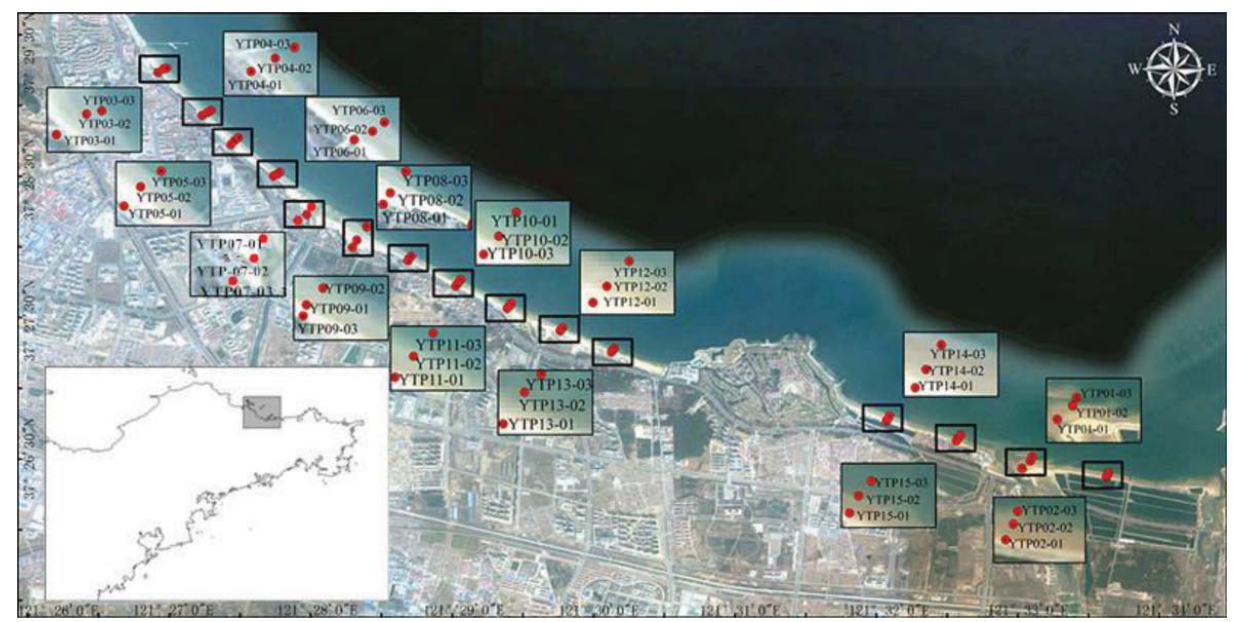

Figure 1. Sampling stations in the intertidal zone of Yantai Sishili Bay. 


\section{Results and discussion}

\section{Concentrations of As and $\mathrm{Hg}$ and comparison with sediment quality guidelines (SQGS)}

Marine Sediment Quality Guidelines (MSQGS) have been established to evaluate sediment toxicity, contamination levels, and ecological risks to aquatic ecosystems. Marine Sediment Quality Standards (MSQS) were published by the State Environmental Protection Administration of China, which includes three criteria for marine sediments that are listed in Table 1. The threshold effect level (TEL) and probable effect level (PEL) were also used to evaluate whether the related heavy metals could affect aquatic organisms; the evaluation criteria are shown in Table 1 (Long et al. 2000; Sundaray et al. 2011).

According to the Chinese National Standard GB18668-2002 for marine sediment quality (SEPA 2002; Table 2), concentrations of As in the surface sediments of the intertidal YSB were lower than the corresponding upper limits of the Class I sediment category, except for the sediment collected from site P02-1 in the dry season (Figure 2). This indicates that, based on sediment quality, the study area is suitable for mariculture, nature reserves, protection of endangered species, and recreational activities. During the dry season, concentrations of As were higher than TEL (Table 2), except for the sediment from site P07-1, which indicated that As may cause potential harm to aquatic organisms. Concentrations in the wet season samples were lower than TEL, indicating a relatively uncontaminated state and that As could pose only limited adverse risks to the study area. As concentrations in the dry season were clearly higher than those in the wet season, due to the fact that higher temperatures favor the release of heavy metals into aquatic environment, and these are more likely to be released to water in the wet season due to the relatively large amount of rainfall compared with the dry season. In general, As concentrations were relatively low in most of the surface sediments of the study area, although toxic effects are more likely to occur during the dry season.

$\mathrm{Hg}$ concentrations in the surface sediments of the YSB intertidal zone were lower than the cutoff levels for Class I sediments and TEL in both the wet and dry seasons (Figure 3), indicative of low $\mathrm{Hg}$ content overall and rare adverse biological effects. The $\mathrm{Hg}$ concentrations during the wet season were higher than those in the dry, because $\mathrm{Hg}$ is not only derived from the sediments but also affected by human activities such as water recreation activities, catering, and construction, which occur more frequently in YSB during the wet season. In summary, $\mathrm{Hg}$ concentrations in YSB pose insignificant adverse biological effects to aquatic ecosystems.

As concentrations in the surface sediments of the YSB intertidal zone were in the range 7.01-23.56 $\mu \mathrm{g} \mathrm{g}^{-1}$ in the dry season, while concentrations of $\mathrm{Hg}$ were in the range $0.00-0.01 \mu \mathrm{g} \mathrm{g}^{-1}$; in the wet season, As concentrations were $1.44-6.17 \mu \mathrm{g} \mathrm{g}^{-1}$, while those of $\mathrm{Hg}$ were $0.00-0.02 \mu \mathrm{g} \mathrm{g}^{-1}$, most of which were even lower than the background value. The reason was that the grain sizes of the sediments were all larger than $63 \mu \mathrm{m}$ (Xu et al. 2017; Yang et al. 2017), leading to relatively low heavy metal adsorption. There was no significant difference between the total content of arsenic and mercury in the high, medium, and low tidal flat, showing no obvious differentiation of natural sedimentary features. The reason was attributed to the strong human activities that changed the hydrodynamic conditions around YSB and the natural sedimentation of tidal flat sediments (Luo et al. 2011). The concentrations of As and $\mathrm{Hg}$ in the study area were comparable to corresponding values reported in other coastal sediments in China. As and $\mathrm{Hg}$ sample values in this study were all almost lower than those found in Jiaozhou Bay, Laizhou Bay, Bohai and the Yellow Sea, 


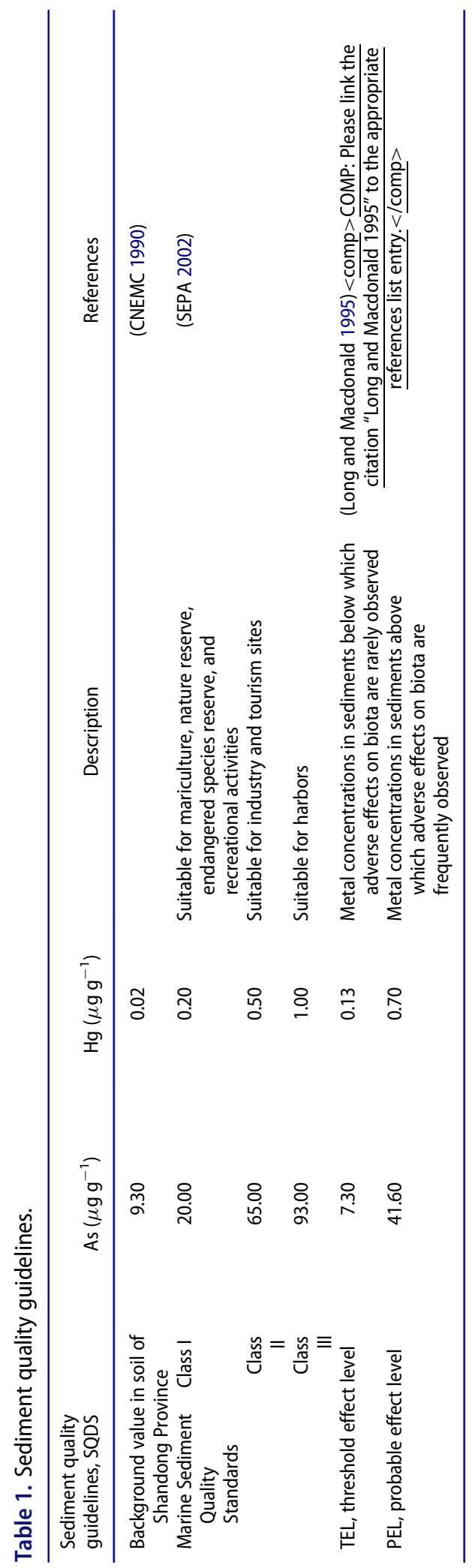


Table 2. Geoaccumulation index $\left(I_{\text {geo }}\right)$ and potential ecological risk factor $\left(E_{r}^{i}\right)$ sediment qualifications.

\begin{tabular}{llll}
\hline$I_{\text {geo }}$ & \multicolumn{1}{c}{ Sediment quality } & \multicolumn{1}{c}{$\mathrm{E}_{\mathrm{r}}^{\mathrm{i}}$} & Sediment quality \\
\hline$I_{\text {geo }} \leq 0$ & Unpolluted & $\mathrm{E}_{\mathrm{r}}^{\mathrm{i}}<40$ & Low risk \\
$0<I_{\text {geo }} \leq 1$ & Unpolluted to moderately polluted & $40 \leq \mathrm{E}_{\mathrm{r}}^{\mathrm{i}}<80$ & Moderate risk \\
$1<I_{\text {geo }} \leq 2$ & Moderately polluted & $80 \leq \mathrm{E}_{\mathrm{r}}^{\mathrm{i}}<160$ & Considerable risk \\
$2<I_{\text {geo }} \leq 3$ & Moderately to highly polluted & $160 \leq \mathrm{E}_{\mathrm{r}}^{\mathrm{i}}<320$ & High risk \\
$3<I_{\text {geo }} \leq 4$ & Highly polluted & $\mathrm{E}_{\mathrm{r}}^{\mathrm{i}} \geq 320$ & Very high risk \\
$4<I_{\text {geo }} \leq 5$ & Highly to very highly polluted & & \\
$I_{\text {geo }}>5$ & Very highly polluted & & \\
\hline
\end{tabular}

Zhifu Bay, the Yellow River Estuary, and Liaodong Bay during the same season (Table 3), further demonstrating that the pollution levels of As and $\mathrm{Hg}$ were relatively low.

Scatter plots were created to explore the relationship between As and Hg concentrations in two seasons, which was similar to the reported work (Zhuang and Gao 2015a,b; Figure 4). There was a strong correlation $(p<0.0001)$ between As concentrations in summer and the corresponding concentrations in autumn, indicating that sources of As do not vary significantly between the two different seasons. The slope (4.98) and intercept $(-0.27)$ of the linear regression equation shown in Figure 4, however, indicate that the source intensity was different between the two seasons. This could be caused by differences in the intensity of discharge, rainfall, and other dynamic conditions in aquatic environments.

There was no significant correlation $(p=0.66)$ between $\mathrm{Hg}$ concentrations in summer and the corresponding samples in autumn, which implies that there are different sources for $\mathrm{Hg}$ between the two seasons. This also implies that $\mathrm{Hg}$ was derived from multiple sources, including factory runoff, urban wastewater discharge, agricultural runoff, and domestic sewage.

\section{Quantification of sediment pollution}

\section{Geoaccumulation index $\left(\mathrm{I}_{\text {geo }}\right)$}

The geoaccumulation index is a contamination index that was created by Müller (Müller 1969), to estimate the enrichment of metals within a sample using the

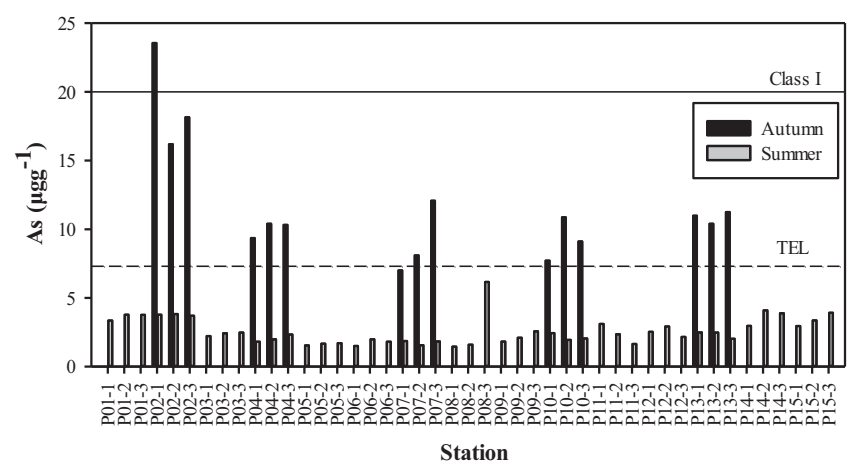

Figure 2. The concentration of As in surface sediments from the intertidal zone of Yantai Sishili Bay (the solid line represents the value of Class I sediment category of China: $20 \mu \mathrm{g} \mathrm{g}^{-1}$; the dashed line represents the value of TEL: $7.3 \mu \mathrm{g} \mathrm{g}^{-1}$ ). 


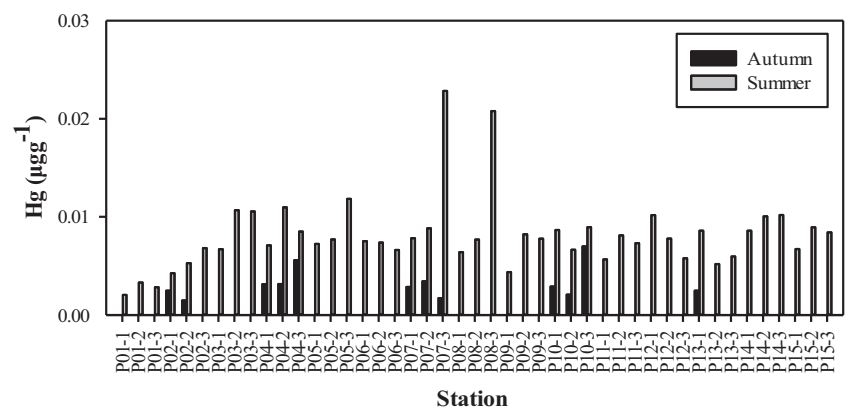

Figure 3. The concentration of $\mathrm{Hg}$ in surface sediments from the intertidal zone of Yantai Sishili Bay.

background level of the metallic component itself, which is defined using the following equation:

$$
I_{\text {geo }}=\log _{2}\left[C_{n} /\left(1.5 \times B_{n}\right)\right]
$$

where $C_{n}$ is the measured concentration of metal $n$ and $B_{n}$ is the geochemical background concentration of metal $n$. The background concentrations of As and $\mathrm{Hg}$ in the soil of Shandong Province were used for this study (CNEMC 1990; Table 1). A factor of 1.5 is used to minimize the effect of possible variations on the background values to the lithological variations in the sediment. The $I_{\text {geo }}$ classes that were used to interpret the level of pollution are shown in Table 2.

As shown in Figure 5, the $I_{\text {geo }}$ values for As were all less than 0, except for three sediments in section P01 during the dry season, indicating that the study area was relatively uncontaminated. The $I_{\text {geo }}$ values for As in the sediments near P01 ranged from 0 and 1, slightly higher than other sites, which was due to the fact that P01 was near the Xianan River Sewage Estuary. The Xinan River Sewage Treatment Plant is near the Gaoling Reservoir Rivers and in the upper reaches of the Xinan River, hence it affects the whole river as well as the estuary. Rivers are directly influenced by anthropogenic activities, which in turn influence the sediments near the river estuaries. $I_{\text {geo }}$ values for $\mathrm{Hg}$ were all below zero (Figure 6), indicating that there was no contamination of mercury due to natural or human activities.

Table 3. Comparison of As and $\mathrm{Hg}$ in the surface sediments of Yantai Sishili Bay.

\begin{tabular}{|c|c|c|c|c|c|c|}
\hline \multirow[b]{2}{*}{ Sampling site } & \multirow[b]{2}{*}{ Sampling time } & \multicolumn{2}{|c|}{ As $\left(\mu \mathrm{g} \mathrm{g}^{-1}\right)$} & \multicolumn{2}{|c|}{$\mathrm{Hg}\left(\mu \mathrm{g} \mathrm{g}^{-1}\right)$} & \multirow[b]{2}{*}{ Reference } \\
\hline & & Range & Mean & Range & Mean & \\
\hline Laizhou Bay & July 2013 & $4.65-9.65$ & & $0.02-0.05$ & & (Zhang and Gao 2015) \\
\hline Bohai and Yellow Sea & 2012 & $3.85-33.20$ & & $0.00-0.07$ & & (Xu et al. 2016b) \\
\hline Yellow River Estuary & May 2011 & $4.33-47.88$ & & $0-0.81$ & & (Jia et al. 2014) \\
\hline Jiaozhou Bay & April 2015 & & $18.91 \pm 0.07$ & & $0.18 \pm 0.10$ & (Zhuang and Gao 2015a) \\
\hline Zhifu Bay & July 2009 & & & & 0.02 & (Wang et al. 2016b) \\
\hline Liaodong Bay & 2009 & $3.10-20.30$ & 8.30 & $0.00-0.40$ & 0.04 & (Hu et al. 2013) \\
\hline \multirow[t]{2}{*}{ Yantai Sishili Bay } & October 2014 & $7.01-23.56$ & 11.70 & $0.00-0.01$ & 0.00 & This study \\
\hline & July 2015 & $1.44-6.17$ & 2.57 & $0.00-0.02$ & 0.01 & \\
\hline
\end{tabular}



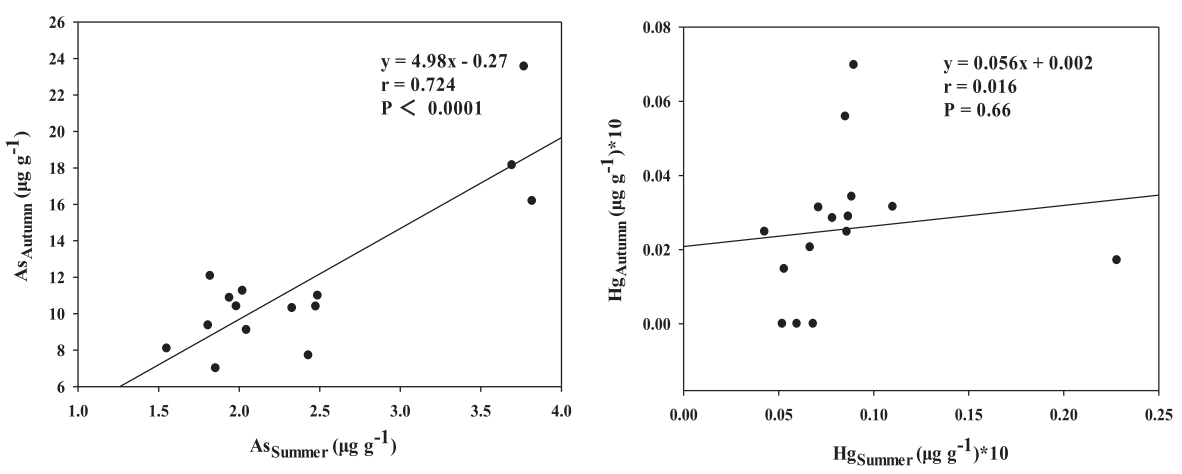

Figure 4. Relationships between the summer and autumn data for $\mathrm{As}$ and $\mathrm{Hg}$ in the surface sediments of the intertidal Yantai Sishili Bay.

\section{Potential ecological risk factor $\left(E_{r}{ }^{i}\right)$}

The potential ecological risk factor $\left(\mathrm{E}_{\mathrm{r}}^{\mathrm{i}}\right)$ was originally developed by Hakanson (Håkanson 1979) and is an index that is widely used in ecological risk assessments for heavy metals in sediments. $\mathrm{E}_{\mathrm{r}}^{\mathrm{i}}$ can be determined using the following formula:

$$
\mathrm{E}_{\mathrm{r}}^{\mathrm{i}}=\mathrm{T}_{\mathrm{r}}^{\mathrm{i}} \times \mathrm{C}_{\mathrm{f}}^{\mathrm{i}}=\mathrm{T}_{\mathrm{r}}^{\mathrm{i}} \times\left(\mathrm{C}_{0}^{\mathrm{i}} / \mathrm{C}_{\mathrm{n}}^{\mathrm{i}}\right)
$$

where $\mathrm{E}_{\mathrm{r}}{ }^{\mathrm{i}}$ is the potential ecological risk for a given element $\mathrm{i}$ and $\mathrm{T}_{\mathrm{r}}{ }^{\mathrm{i}}$ is the toxic response factor (the $\mathrm{T}_{\mathrm{r}}{ }^{\mathrm{i}}$ of As is 10; the $\mathrm{T}_{\mathrm{r}}{ }^{\mathrm{i}}$ of $\mathrm{Hg}$ is 40 ). $\mathrm{C}_{\mathrm{f}}{ }^{\mathrm{i}}, \mathrm{C}_{\mathrm{o}}{ }^{\mathrm{i}}$, and $\mathrm{C}_{\mathrm{n}}{ }^{\mathrm{i}}$ are the contamination factor, the concentration in sediment, and the background reference level for the element $i$, respectively. Like the $I_{\text {geo }}$ calculation, the corresponding background concentrations for As and $\mathrm{Hg}$ in the soil of Shandong Province were adopted to calculate the $\mathrm{E}_{\mathrm{r}}^{\mathrm{i}}$ values used in this study. $\mathrm{E}_{\mathrm{r}}^{\mathrm{i}}$ values were classified into five major groups in Table 2.

The $\mathrm{E}_{\mathrm{r}}^{\mathrm{As}}$ results showed that there was a low environmental risk due to As contamination at all sites in both seasons, and the values of $\mathrm{E}_{\mathrm{r}}{ }^{\mathrm{As}}$ in the dry season were higher than those in wet season (Figure 7). The calculated $\mathrm{E}_{\mathrm{r}}^{\mathrm{Hg}}$ values are shown in Figure 8. Values for $\mathrm{E}_{\mathrm{r}}^{\mathrm{Hg}}$ at all sampling sites were lower than 40, except for P07-3 and P08-3 in the wet season,

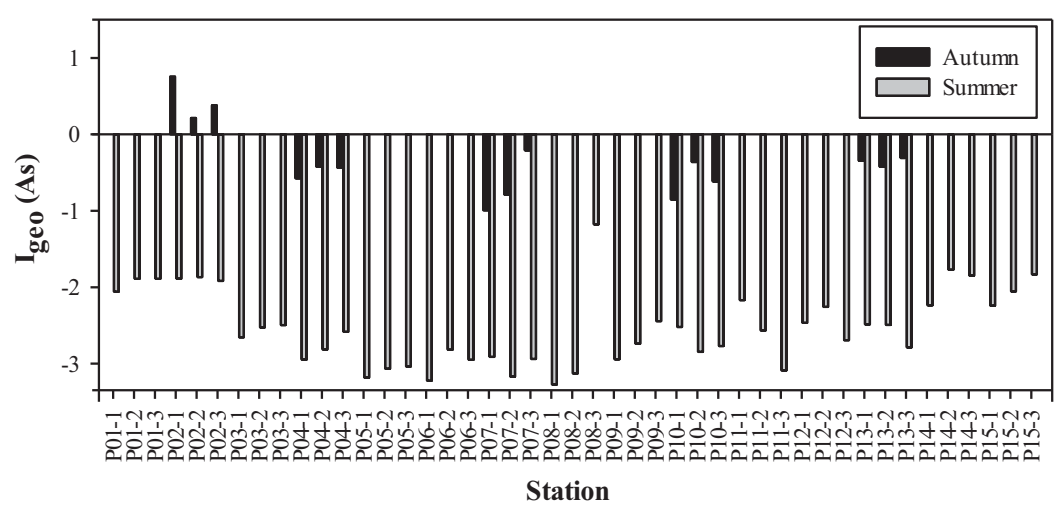

Figure 5. The $I_{\text {geo }}$ value of As in surface sediments from the intertidal zone of Yantai Sishili Bay. 


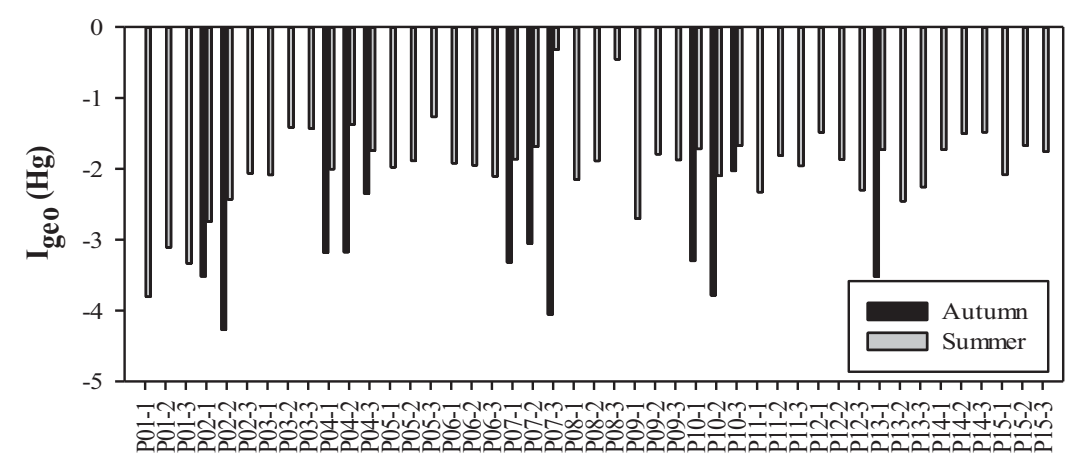

Station

Figure 6. The $I_{\text {geo }}$ value of $\mathrm{Hg}$ in surface sediments from the intertidal zone of Yantai Sishili Bay.

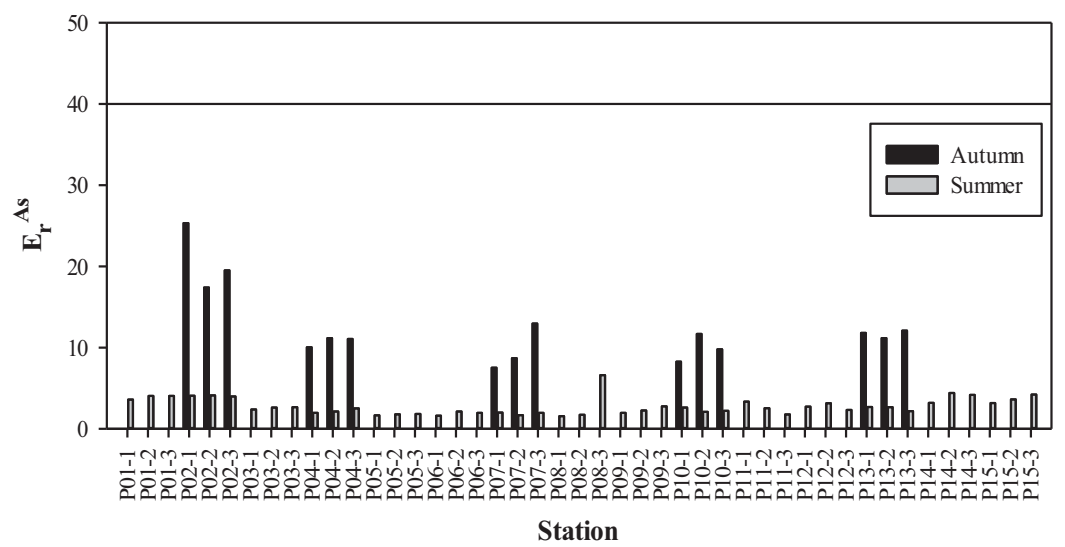

Figure 7. The $E_{r}^{i}$ value of As in surface sediments from the intertidal zone of Yantai Sishili Bay (the solid line represents that the value of $E_{r}^{i}$ is 40 ).

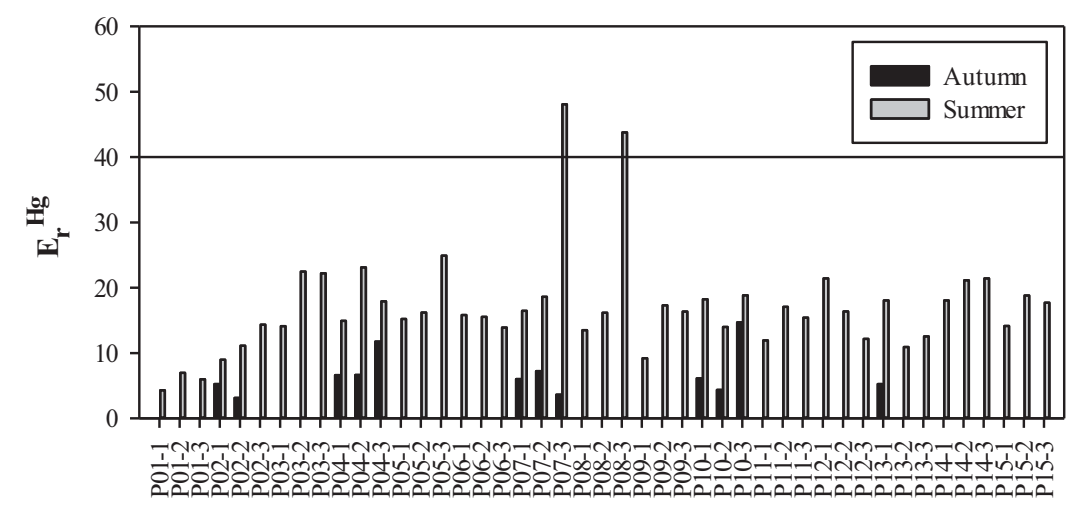

Station

Figure 8. The $\mathrm{E}_{\mathrm{r}}^{\mathrm{i}}$ value of $\mathrm{Hg}$ in surface sediments from the intertidal zone of Yantai Sishili Bay (the solid line from the top to the bottom represents that the value of $E_{r}^{i}$ is 40). 
representative of a low potential ecological risk. $\mathrm{E}_{\mathrm{r}}^{\mathrm{Hg}}$ values at sites P07-3 and P08-3 were slightly higher than 40 , indicating a moderate level of potential environmental risk, which was due to the influence of the Guangdang River. This river is a landscape feature of the Yantai Laishan District and the Guangdang River park along the banks is an important location for public entertainment and recreation. Three direct sewage drainage channels adversely affect the water quality of the Guangdang River. However, in light of this problem, provincial planning departments have made an effort to lay runoff and sewage pipeline infrastructure in a comprehensive transformation to put an end to water contamination.

\section{Conclusions}

As and $\mathrm{Hg}$ concentrations in the surface sediments of the YSB intertidal zone were measured to investigate their levels of contamination and potential ecological risk. Results demonstrated that As was in a practically uncontaminated status in the study area with a low potential ecological risk, posing little adverse biological effects on aquatic ecosystems. Hg also had little evidence of contamination with low environmental risk, posing little adverse biological threat to aquatic ecosystems. In conclusion, this study indicated that the sediment quality in the surface sediments of intertidal zone of YSB was generally good with respect to contamination levels of As and $\mathrm{Hg}$.

\section{Acknowledgment}

We thank MogoEdit for its linguistic assistance during the preparation of this manuscript.

\section{Funding}

This research was supported by the Youth Innovation Promotion Association (2011170) and the Equipment Development Project (YZ201558) of Chinese Academy of Sciences and the Basic Survey of the Ministry of Science and Technology (2014FY10600) of China.

\section{References}

CNEMC. 1990. Chinese Elemental Background Values for Soils. Chinese Environmental Science Press, Beijing, China

Deng H, Wang D, Chen Z, et al. 2013. A comprehensive investigation and assessment of mercury in intertidal sediment in continental coast of Shanghai. Environ Sci Pollut Res Int 20:6297-305. https://doi.org/10.1007/s11356-013-1665-2

Dong Z, Liu D, Wang Y, et al. 2012. A report on a Moon Jellyfish Aurelia aurita bloom in Sishili Bay, Northern Yellow Sea of China in 2009. Aquat Ecosyst Health Manag 15:161-7

Gati G, Pop C, Brudaşcă F, et al. 2016. The ecological risk of heavy metals in sediment from the Danube Delta. Ecotoxicology 25:688-96. https://doi.org/10.1007/s10646-016-1627-9

Håkanson L. 1979. An ecological risk index for aquatic pollution control - A sedimentological approach. Water Res 14:975-1001. https://doi.org/10.1016/0043-1354(80)90143-8

Hao Y, Tang D, Yu L, et al. 2011. Nutrient and chlorophyll a anomaly in red-tide periods of 2003-2008 in Sishili Bay, China. Chin J Oceanology Limnol 29:664-73. https://doi.org/10.1007/s00343-011-0179-3

Haris H, Aris AZ, and Mokhtar MB. 2017. Mercury and methylmercury distribution in the intertidal surface sediment of a heavily anthrophogenically impacted saltwater-mangrove-sediment interplay zone. Chemosphere 166:323-33. https://doi.org/10.1016/j.chemosphere.2016.09.045 
$\mathrm{Hu} \mathrm{B}, \mathrm{Li}$ J, Zhao J, et al. 2013. Heavy metal in surface sediments of the Liaodong Bay, Bohai Sea: Distribution, contamination, and sources. Environ Monit Assess 185:5071-83. https://doi.org/ 10.1007/s10661-012-2926-0

Jia H, Sun K, Zhang J, et al. 2014. Distribution and pollution assessment of heavy metals in surface sediment in yellow river estuary and the adjacent sea Area. Appl Mech Mater 665:464-8. https:// doi.org/10.4028/www.scientific.net/AMM.665.464

Li B, Keesing JK, Liu D, et al. 2013. Anthropogenic impacts on hyperbenthos in the coastal waters of Sishili Bay, Yellow Sea. Chin J Oceanology Limnol 31:1257-67. https://doi.org/10.1007/s00343013-2173-4

Li H, Kang X, Li X, et al. 2017. Heavy metals in surface sediments along the Weihai coast, China: Distribution, sources and contamination assessment. Mar Pollut Bull 115:551-8. https://doi.org/ 10.1016/j.marpolbul.2016.12.039

Li M, Yang W, Sun T, et al. 2016. Potential ecological risk of heavy metal contamination in sediments and macrobenthos in coastal wetlands induced by freshwater releases: A case study in the Yellow River Delta, China. Mar Pollut Bull 103:227-39. https://doi.org/10.1016/j.marpolbul.2015.12.014

Lin Y, Meng F, Du Y, et al. 2016. Distribution, speciation, and ecological risk assessment of heavy metals in surface sediments of Jiaozhou Bay, China. Human Ecol Risk Assess: An Int J 22:1253-67. https://doi.org/10.1080/10807039.2016.1159503

Liu R, Men C, Liu Y, et al. 2016. Spatial distribution and pollution evaluation of heavy metals in Yangtze estuary sediment. Mar Pollut Bull 110:564-71. https://doi.org/10.1016/j.marpolbul.2016.05.060

Liu Z, Li P, Zhang X, et al. 2014. Distribution and source of main contaminants in surface sediments of tidal flats in the Northern Shandong Province. J Ocean Univ China 13:842-50. https://doi.org/ 10.1007/s11802-014-2390-2

Long ER and Macdonald DD. 1995. Incidence of adverse biological effects within ranges of chemical concentrations in marine and estuary sediments. Environ Manage 19:81-97. https://doi.org/ 10.1007/BF02472006

Long ER, MacDonald DD, Severn CG, et al. 2000. Classifying probabilities of acute toxicity in marine sediments with empirically derived sediment quality guideline. Environ Toxicol Chem 19:2598601. https://doi.org/10.1002/etc.5620191028

Luo X, Tian J, Yanf J, et al. 2011. Distribution characteristics of heavy metals and nutrient elements in inter-tidal surface sediments of Yellow River estuary. Ecol Environ Sci 20(5):892-7 (in Chinese)

Müller G. 1969. Index of geo accumulation in sediments of the Rhine River. GeoJournal 2:108-18

Pereira TDS, Moreira ITA, de Oliveira OMC, et al. 2015. Distribution and ecotoxicology of bioavailable metals and As in surface sediments of Paraguacu estuary, Todos os Santos Bay, Brazil. Mar Pollut Bull 99:166-77. https://doi.org/10.1016/j.marpolbul.2015.07.031

Qian X, Liang B, Fu W, et al. 2016. Polycyclic aromatic hydrocarbons (PAHs) in surface sediments from the intertidal zone of Bohai Bay, Northeast China: Spatial distribution, composition, sources and ecological risk assessment. Mar Pollut Bull 112:349-58. https://doi.org/10.1016/j. marpolbul.2016.07.040

SEPA (State Enviromental Protection Administration of China). 2002. Marine Sediment Quality (GB 18668-2002). Standards Press of China, Beijing, China

Sundaray SK, Nayak BB, Lin S, et al. 2011. Geochemical speciation and risk assessment of heavy metals in the river estuarine sediments - A case study: Mahanadi basin, India. J Hazard Mater 186:1837-46. https://doi.org/10.1016/j.jhazmat.2010.12.081

Wang H, Liu R, Wang Q, et al. 2016a. Bioavailability and risk assessment of arsenic in surface sediments of the Yangtze River estuary. Mar Pollut Bull 113:125-31. https://doi.org/10.1016/j. marpolbul.2016.08.076

Wang Z, Lu X, and Zhang K. 2016b. Distribution and contamination of metals and biogenic elements in sediments from Zhifu Bay of the Yellow Sea, China. J Environ Sci 41:6-15. https://doi.org/ 10.1016/j.jes.2015.06.009

Xu F, Qiu L, Cao Y, et al. 2016a. Trace metals in the surface sediments of the intertidal Jiaozhou Bay, China: Sources and contamination assessment. Mar Pollut Bull 104:371-8. https://doi.org/10.1016/ j.marpolbul.2016.01.019 
Xu L, Wang T, Ni K, et al. 2013. Ecological risk assessment of arsenic and metals in surface sediments from estuarine and coastal areas of the southern bohai sea, China. Human Ecolog Risk Assessment: An Int J 20:388-401. https://doi.org/10.1080/10807039.2012.762281

Xu S, Di B, Wang Y, et al. 2017. Spatial distribution of benthic diatom in the typical intertidal zones in China. Haiyang Xuebao 39:95-113 (in Chinese)

$\mathrm{Xu} \mathrm{X}$, Cao Z, Zhang Z, et al. 2016b. Spatial distribution and pollution assessment of heavy metals in the surface sediments of the Bohai and Yellow Seas. Mar Pollut Bull 110:596-602. https://doi.org/ 10.1016/j.marpolbul.2016.05.079

Yang X, Wu P, Yin A, et al. 2017. Distribution and source analysis of heavy metals in soils and sediments of Yueqing Bay basin, East China Sea. Mar Pollut Bul 115:489-97. https://doi.org/10.1016/j. marpolbul.2016.11.046

Yi Y, Sun J, Tang C, et al. 2016. Ecological risk assessment of heavy metals in sediment in the upper reach of the Yangtze River. Environ Sci Pollut Res Int 23:11002-13. https://doi.org/10.1007/ s11356-016-6296-y

Zhang J and Gao X. 2015. Heavy metals in surface sediments of the intertidal Laizhou Bay, Bohai Sea, China: Distributions, sources and contamination assessment. Mar Pollut Bull 98:320-7. https://doi. org/10.1016/j.marpolbul.2015.06.035

Zhao G, Lu Q, Ye S, et al. 2016. Assessment of heavy metal contamination in surface sediments of the west Guangdong coastal region, China. Mar Pollut Bull 108:268-74. https://doi.org/10.1016/j. marpolbul.2016.04.057

Zhuang W and Gao X. 2014. Assessment of heavy metal impact on sediment quality of the Xiaoqinghe estuary in the coastal Laizhou Bay, Bohai Sea: Inconsistency between two commonly used criteria. Mar Pollut Bull 83:352-7. https://doi.org/10.1016/j.marpolbul.2014.03.039

Zhuang W and Gao X. 2015a. Distributions, sources and ecological risk assessment of arsenic and mercury in the surface sediments of the southwestern coastal Laizhou Bay, Bohai Sea. Mar Pollut Bull 99:320-7. https://doi.org/10.1016/j.marpolbul.2015.07.037

Zhuang W and Gao X. 2015b. Distribution, enrichment and sources of thallium in the surface sediments of the southwestern coastal Laizhou Bay, Bohai Sea. Mar Pollut Bull 96:502-7. https://doi. org/10.1016/j.marpolbul.2015.04.023 